\title{
RETÓRICA DE INFLUÊNCIA SOCIAL E NEGOCIAÇÃO, SEGUNDO PODER/RECONHECIMENTO NA SOCIEDADE
}

\author{
Edson Alves de Souza Filho ${ }^{\star}$ \\ Universidade Federal do Rio de Janeiro, Rio de Janeiro, RJ, Brasil
}

\section{ReSUMO}

Estudamos o modo denegociar a pressão provocada por personagens considerados mais oumenos poderosos/reconhecidos na sociedade perante a identificaçãoétnica do participante. Tratamos os fenômenos segundo as teorias de influência social ou retóricas de ação social. Trabalhamos com situações simuladas de pressão para recriar experiências possiveis de interação. Participaram 207 estudantes de ensino médio de escolas públicas estaduais, identificados como negros, brancos e morenos. Os resultados indicaram retóricas/ações como recusas, aceitação e não decisão às pressões. As retóricas/ações antecipadas foram de cordialidade, interesse próprio, hostilidade, interesse do outro. Os brancos tenderam a aceitar mais a pressão de personagens poderosos e os negros, em menor proporção, a recusar. Quanto aos personagens minoritários, houve aceitação da pressão nos grupos, indicando menor controvérsia. Discutimos os resultados nos marcos da dinâmica de relações entre grupos na sociedade.

Palavras-chave: influência social; retórica de ação; grupos étnicos.

\section{RHETORIC OF SOCIAL INFLUENCE AND NEGOTIATION, ACCORDING TO POWER/RECOGNITION IN SOCIETY}

\begin{abstract}
We studied the way pressure inflicted by more or less powerful/recognized people in society is negotiated by ethnically identified participants. We considered these phenomena drawing on social influence theories or social action rhetoric. We worked with simulated pressure situations in order to recreate possible experiences of interaction. 207 public high school students identified with Black, White and Mixed people took part in this research. The results showed rhetoric/ action of rejection, acceptation and non decision to pressures. The rhetoric/action anticipated were those of cordiality, own interest, hostility and other's interest. Whites tended to accept more the pressure of powerful people; and Blacks, to a lesser extent, to reject it. Regarding minority people, we found that all groups accepted their pressure, pointing out there is less controversy. We discussed the results within the frame of intergroup relations in the dynamics in society.

Keywords: social influence; action rhetoric; ethnic groups.

\footnotetext{
^Endereço para correspondência: Universidade Federal do Rio de Janeiro, Instituto de Psicologia, Curso de Pós-Graduação em Psicologia. Av. Pasteur, 250 - Praia vermelha. 22290-240 - Rio de Janeiro, RJ - Brasil.E-mail: edsouzafilho@gmail.com
} 


\section{INTRODUÇÃo}

Historicamente, o estudo de influência social foi muito marcado tanto pelo poder daquele que pretende influenciar, como pela situação de dependência daquele que está em via de ser influenciado, sem os quais a efetividade do processo diminuiria (FRENCH; RAVEN, 1959). Após os estudos teóricos e empíricos de Moscovici (2011[1979]), esse quadro começou a se modificar, com a formalização de outra variável: o estilo de comportamento ou retórica de influência, sem a qual uma mensagem nova, fora do padrão sociocultural preexistente, não conseguiria influenciar.

Assim, em situação de laboratório, participantes foram chamados a identificar cores e encontravam outros participantes, alguns combinados com o experimentador para se comportar de modo diferente durante as sessões coletivas de percepção de cores (MOSCOVICI, 2011[1979]). A cor projetada era azul, mas os "combinados" com o experimentador diziam em voz alta, sistematicamente: verde! $\mathrm{O}$ estilo de comportamento nesse caso seria a consistência, em que se comunica mensagem de modo coerente, autoconfiante etc. Terminado o experimento os participantes eram convidados a participar de outra pesquisa com outro investigador na qual eram instruídos a identificar cores com outro material, porém separados por divisórias e apenas escrevendo a resposta individualmente; quando eles tenderam a dizer a cor verde diante de discos de tonalidades de azul. Moscovici (2011[1979]) levantou a hipótese de que a influência da minoria no laboratório teria provocado um conflito explícito com a maioria cuja resolução só se daria ao nível latente com a possível incorporação da mensagem minoritária internamente. No mesmo livro, foram relatadas outras pesquisas similares em que a operacionalização do estilo de comportamento foi na forma de repetição entre "combinados" da mesma resposta fora do padrão convencional, constituindo, segundo o mesmo autor, em consistência interindividual, mas também foi examinado o impacto da consistência intraindividual, quando a mesma pessoa afirmava sozinha mais de uma vez a resposta fora do padrão. Para Moscovici (2011[1979]), o impacto da retórica minoritária ativa teria provocado a influência, mesmo sendo a partir de mensagem fora dos padrões socioculturais. Já a mensagem majoritária - no sentido de mensagem/proposta convencionalmente adotada/apoiada pela maioria numérica do ambiente social; ou mesmo aquela preconizada por alguém que detém poder/reconhecimento - , é, em geral, associada à troca de interesses e seguindo as normas existentes; para o mesmo autor mencionado, seria aceita sem conflito interno, no sentido de não ocorrer confronto entre normas. Em realidade, o sujeito se submeteria à pressão de poder para evitar punição ou receber benefício imediato ou posterior, independente do mérito ou valor da proposta, eventualmente partilhados socialmente.

Os estudos antes sucintamente relatados foram feitos em ambientes de laboratório para realizar tarefas algo artificiais. Nesse sentido, Apfelbaum (1997) comentou a relativa lacuna de pesquisas dessa área a partir de conteúdos históricos e culturais mais "reais", que tenderam, basicamente, a trabalhar com instrumentos de pesquisa que esvaziam tais conteúdos envolvidos nos fenômenos levantados. Mais recentemente, Moscovici e Pérez (2007) propuseram outro tipo 
de influência minoritária, que não se contrapõe às normas existentes, mas apenas a retomada/manutenção das normas e/ou valores já estabelecidos na sociedade, postos hierarquicamente em posição inferior; como alguns princípios humanitários ou religiosos, que são eventualmente usados como retóricas de influência social. Segundo os mesmos autores, as minorias mencionadas tenderiam atualmente a se apresentar como "vítimas" de desigualdades e injustiças praticadas, as quais gerariam mais sentimento de culpa; cuja solução implicaria em ações reparadoras, mas não alterariam a mencionada hierarquia de valores e normas sociais usadas como argumento, diminuindo o impacto e a durabilidade da influência; como certas denúncias que não enfrentam o conflito com as normas majoritárias.

O fato de Moscovici (2011[1979]) e colaboradores evidenciarem alguns efeitos importantes da pressão social minoritária veiculada de formas específicas sem uso de poder, algumas questões ficaram menos esclarecidas. Uma delas refere-se às possíveis implicações psicossociais de confrontar-se com personagens dotados de poder/reconhecimento social maior, menor ou nenhum, mas que não se desviam explicitamente das normas sociais, ainda que alguns possam apresentar características que os tornem anômicos; no sentido de não seguirem as normas por impossibilidade, como portar deficiência, traço físico considerado fora do padrão, entre outros; não por decisão de transgredir ou propor algo incompatível com as normas vigentes. Portanto, seria necessário averiguar separadamente a questão do poder de recompensar/punir dos personagens daquele que deriva de crenças e convenções sociais consideradas mais gerais e adotadas pela maioria numérica, implicando em poder; em relação às quais os próprios personagens minoritários não seriam capazes de recompensar/punir - o que poderia advir indiretamente de outros personagens ou, quando internalizada, do próprio sujeito (LEWIN, 1948).

Por outro lado, o próprio status de reconhecimento do participante pesquisado poderia ser considerado uma dimensão importante a ser avaliada em termos de tomada de decisão em relação a uma pressão de influência majoritária, minoritária-majoritária ou minoritária quanto a normas/reconhecimentos sociais; o que praticamente foi pouco estudado. Nesse sentido, uma hierarquia social muito duradoura no Brasil refere-se aos grupos étnicos, os quais dizem respeito aos brancos, negros e outros grupos classificados segundo denominações em negociação, que desfrutam de relações de poder/reconhecimento desiguais na sociedade (BASTIDE, 1971; MUNANGA, 1998; OLIVEIRA, 1999; SEYFERTH, 1996). A questão da denominação de grupos étnicos minoritários no Brasil tem sido objeto de debate acadêmico e fora dele (MAGGI, 1996; SCHWARTZMAN, 2004). Sabemos que as denominações de grupos étnicos minoritários são, com frequência, produzidas por grupos majoritários, em termos de poder e influência. Assim, nos EUA Philogène (1997) mostrou que a denominação de Black imposta aos negros norte-americanos era aceita por uma boa parcela deles apesar de estar associada a conotações simbólicas negativas, até que surgisse uma denominação produzida pelos próprios negros, de African-American, que passou a ser vista de modo mais positivo mesmo entre brancos do mesmo país. No Brasil, os levantamentos do Instituto Brasileiro de Geografia e Estatística (IBGE) (1976; Cf. SCHWARTZMAN, 2004) têm mostrado a variabilidade de denominações raciais de brasilei- 
ros, indicando que este campo simbólico está em transformação, cabendo mais pesquisas. Aqui é bom lembrar que este fenômeno é internacional, não por imposição de uma cultura sobre outras, necessariamente, mas antes de tudo porque existe identificação de causas e lutas sociais. Citaríamos o impacto que causou no espaço público o slogan "Black is beautiful" a partir dos anos 1960, entre outros que foram lançados por minorias ativas. Contudo, não foi nosso objetivo estudar as autodenominações étnicas no Brasil em si, mas levar em conta de forma "minimalista", os grupos de autodenominações étnicas, explicitamente mencionadas, para daí poder estudar algumas possíveis interações sociais. De todo jeito, é bom lembrar que as autodenominações têm servido pra detectar desigualdades sociais oriundas das estruturas étnicas existentes na sociedade. Assim, no fim do século XIX, 80\% dos brancos no Brasil eram analfabetos (FAUSTO, 1994); mas já no Censo de 2000 essa situação estava bastante modificada, constituindo uma importante "ascensão educacional". Assim, segundo dados do mencionado Censo do IBGE, os brancos analfabetos eram 10,9\% (de uma população de 82,4 milhões); enquanto os negros eram $23,2 \%$ (de uma população de 9,8 milhões); e os pardos de 21,1\%, (de uma população de 58,7 milhões). Ademais, 9,9\% dos brancos haviam atingido escolaridade universitária, em contraste com os negros e pardos, entre os quais as proporções eram bem menores - $2,1 \%$ e $2,4 \%$, de negros e pardos, respectivamente - (IBGE, 2000). Tendo em vista esse quadro educacional sumário - levando em conta que para a população em geral a educação constitui uma das principais formas de aumentar poder e influência na sociedade -; supomos que os brancos sejam o grupo mais envolvido, tanto em apoiar quanto ampliar poder social, não necessariamente no sentido da ascensão educacional ou socioeconômica, mas, frequentemente, a fim de manter certa ordem simbólica que lhes garanta, por exemplo, ascendência, liderança moral na sociedade (LÉVY-STRAUSS, 1970). Trata-se de alguma forma de competição social numa sociedade em transformação em que todos os instrumentos são usados para atingir certos objetivos, independente de proeminência de valores, formas de negociar a distribuição de poder. Para tanto, há que explicitar quanto ocultar poder, assim como ampliá-lo a partir de ação social individual e/ou coletiva, visando resultados de médio e longo prazo (MOSCOVICI, 2011[1979]). Nesse sentido, há uma luta para ocultar interesses e se apresentar como desligado em relação aos mesmos. Isso é feito principalmente a partir de retóricas de influência, como a cordialidade ou apelo sentimental, segundo certa convenção social tornada "regra de boas maneiras", que modificam o sentido e natureza das propostas negociadas entre personagens sociais de níveis de poder social desiguais, redundando em algo que equivaleria à renúncia à pressão social, que é a principal forma de ação minoritária no espaço público; mesmo quando exercida sem violência ou propondo outras formas de ação voltadas para dentro do grupo como solidariedade, entre outras, que geram conflito social (MOSCOVICI, 2011[1979]).

Como existe uma consciência a respeito dessa hierarquia social - que é mantida a partir de várias ações sociais (BASTIDE, 1971) - , isso faz com que os grupos elaborem diferentes formas de (re)ação à pressão social de personagens poderosos, mais ou menos poderosos e sem poder. As formas existentes de en- 
frentar a referida hierarquia historicamente vão da aceitação da desigualdade à recusa da mesma, passando por formas de não decisão (SOUZA FILHO, 2011). Na situação corriqueira até recentemente existiriam bloqueios de expressão pública das recusas com relação aos grupos poderosos, que poderiam implicar em perdas de oportunidades e retaliações. No nível mais privado, os grupos minoritários seriam aqueles que mais experimentariam frustrações diante da situação social de desigualdades, acarretando algumas vezes em agressão social (DOLLARD et al, 1939), nas suas várias formas; o que seria modulado em função de normas e legitimidade de manifestação da mesma, segundo o indivíduo ou grupo social (BERKOWITZ, 1969; TAJFEL, 1978). Até certo ponto, podemos considerar que numa ordem social baseada em uma hierarquia étnica, em que a maioria dos poderosos é oriunda do grupo dos que se definem como brancos, uma pressão dos poderosos sobre os não poderosos tornar-se-ia imediatamente em ação inter-étnica, implicando em conflito de normas e ideologias a respeito, mesmo que esta dimensão esteja invisível socialmente.

O detalhamento da elaboração da forma de enfrentar o conflito oriundo de pressão para exercer influência social e sua negociação foram pouco estudados, cabendo até mesmo uma formalização a respeito. Antes é preciso dizer que a pressão social não constitui uma ordem ou comando social, mas pode sugerir, para alguns, algo gerador de reações típicas de quem está sendo ameaçado em termos de perda de liberdade. Sabemos que o termo pressão foi utilizado por teóricos da influência social como forma de exercer poder de uns sobre outros. $\mathrm{Na}$ abordagem aqui adotada, o termo pressão inclui a recusa, entre outras formas de afirmação de uma posição divergente em relação a quem propõe uma ação/ pensamento (MUGNY; PAPASTAMOU, 1982). Tal forma de agir é geradora de conflito, uma vez que existe em muitas sociedades expectativas de manutenção de consensos explícitos e implícitos, parciais ou mais gerais. Enfim, podemos dizer que a estrutura social existente na sociedade brasileira tem sido acompanhada pela difusão de normas-ideologias de modo a não tratar de desigualdades étnicas, muito menos de formas de ação autônoma individual; eventualmente sintonizadas às ideias/práticas adotadas por movimentos sociais, constituindo pressões de mudança social minoritária. No lugar disso, há mais destaque para formas de ação que dependam de grupos poderosos, ou quase-poderosos, caracterizados por lutas sociais consideradas mais "gerais". Destarte muitos grupos poderiam até mesmo pretender que são "desinteressados" ou altruístas (MOSCOVICI, 1994); enquanto a outros caberia o papel de confrontadores do sistema praxeológico e/ou ideológico vigente, muitas vezes sem propor uma ação/pensamento de substituição, mas simplesmente recusando aquilo que é mais convencional socialmente, o que provoca o conflito com implicações possíveis na avaliação da sua inserção social.

Vários estudos sobre relações sociais indicaram a importância para a elaboração e expressão de comportamentos/mentalidades em situação de interação entre grupos, como os de Tajfel (1981) e Doise (1979). No âmbito brasileiro, apesar da diversidade cultural, poucos trabalhos foram feitos com esses propósitos, configurando certa lacuna de investigação. Em parte, porque o problema intergrupal ainda é tratado de modo a diluir algumas fronteiras grupais, enquanto outras 
delas são sistematicamente demarcadas/reforçadas ao longo da história, que é a ótica e meta majoritária e, mesmo da minoria com autoestima alta e maior consciência de suas diferenças (MOSCOVICI; PAICHELER, 1978). Mesmo assim, nas últimas décadas houve surgimento e consolidação de novos grupos religiosos, partidários, entre outros, indicando um dinamismo social que exige trabalhos da psicologia social e, em especial, de influência social e relações intergrupais.

Procurando superar essas tendências, elaboramos um conjunto de pesquisas, de observação sistemática, em que pudéssemos averiguar interações sociais quando a dimensão poder/reconhecimento do interlocutor ficasse explicitada, em situações variadas, assim como por diferentes personagens, sem intenção de estudar papéis sociais no sentido clássico do conceito, uma vez que a vida cotidiana hoje é mais fluída e menos cristalizada do que em passado recente. Por outro lado, comparar sujeitos autodefinidos étnica e racialmente no Brasil constitui por si só um empreendimento necessário, apesar de alguns considerarem que essas outras dimensões poderiam ser tratadas como epifenômenos para o movimento da sociedade, como já dissemos. Apesar disso, devido à escassa participação pública dos negros no Brasil, podemos supor certa diferenciação, sobretudo no que se refere às interações com personagens poderosos. Isso porque supomos que a expectativa de mobilidade social seja muito maior entre brancos, o que merece mais estudos e verificações empíricas.

A partir do que os autores aqui lembrados elaboraram, formulamos algumas hipóteses que foram testadas com uma pesquisa empírica:

a) Os autodefinidos como brancos tenderiam a apresentar (re)ações de aceitação da pressão provocadas por detentores de mais poder, tendo em vista a maior expectativa de alianças, colaborações com os mesmos, enquanto os demais grupos étnicos - principalmente entre os negros -, esta tendência seria menos acentuada;

b) Já os personagens mais ou menos poderosos e não poderosos gerariam respostas mais niveladas entre os grupos étnicos, uma vez que o poder social menor ou nulo dos mesmos seria a principal variável para decidir a respeito da submissão ou não à pressão.

\section{Método}

\section{Participantes}

Participaram da pesquisa, realizada em 1998 e 1999, 207 estudantes de ensino médio de escolas públicas estaduais da cidade do Rio de Janeiro. A decisão sobre a escolha das escolas foi mais em função das suas localizações, próximas a comunidades (favelas) da cidade, de modo a ter acesso a grupos étnicos diversificados, constituindo amostras acidentais. Trabalhamos com três estabelecimentos localizados em três pontos da cidade: centro, zona norte e zona sul, abrangendo os dois últimos seguimentos do ensino médio. 
Em pesquisa realizada pelo IBGE em 1998 e relatada por Schwartzman (2004) junto a 90 mil pessoas, foram apresentadas as denominações usualmente usadas pelo mesmo órgão (branca, preta, amarela, parda, indígena, sem resposta) para serem consideradas em termos de pertinência ou aceitação para o próprio participante. Enquanto os brancos confirmaram o termo "branco" em 91,08\%; os morenos, por sua vez, confirmaram serem denominados como "pardo" em $53,96 \%$; os pretos e negros, enfim, confirmaram a denominação "preto" em $44,41 \%$ e 30,92\%, respectivamente (SCHWARTZMAN, 2004, p. 105). Tendo em vista que as aceitações dessas denominações raciais/étnicas tenham sido relativamente baixas, como em outro levantamento feito pelo IBGE (1976), preferimos formular uma pergunta aberta que, tanto sugeria uma autodenominação "preestabelecida" quanto permitia outros formatos emergirem. Assim, o instrumento que utilizamos para coleta de dados continha um item destinado a reunir informações pessoais sobre etnia/raça, que trazia as seguintes instruções "Definição racial/étnica pessoal (descreva como quiser, através de traços físicos, como cor da pele: branca, negra, morena ou outro):". Para evitar classificação arbitrária, foram incluídos na pesquisa aqui relatada apenas os participantes que explicitamente adotaram a autodenominação em forma escrita ou sublinhando uma das opções oferecidas, ou seja, negro, branco e moreno. Enfim, os participantes incluídos se autodenominaram como negros $(n=39)$, brancos $(n=80)$ e morenos $(n=88)$.

A média de idade dos participantes foi de 16,39 anos (Desvio-padrão de 2,71). Já a distribuição dos grupos formados em termos de etnia/raça quanto a sexo/gênero foi como se segue: negros (feminino $=75,6 \%$; masculino $=24,3 \%$ ), brancos (feminino $=47,5 \%$; masculino $=52,4 \%$ ), morenos (feminino $=68,4 \%$; masculino $=31,5 \%$ ). A escolaridade dos pais foi classificada segundo níveis alcançados, completo ou não, indo do analfabeto $=0$, fundamental $=1$, médio $=2$, superior $=3$, sendo que as mães tiveram média de $1,75(\mathrm{DP}=0,82)$, enquanto os pais $1,92(\mathrm{DP}=0,85)$. Enfim, sobre religião, os participantes declararam serem católicos (46,3\%); evangélicos e similares (26,3\%); espíritas (5\%); sem religião (incluindo ateus) $(11,3 \%)$; umbanda/macumba $(1,9 \%)$; e outros não responderam $(9,4 \%)$.

\section{Instrumento e procedimento}

Um questionário (Anexo I) foi concebido especialmente para permitir observar situações em que o participante vive uma pressão hipotética provocada pelo contato com um personagem portador de uma dimensão psicossocial que pode ser identificado como pertencente a um grupo majoritário, majoritário-minoritário e minoritário. Aqui é bom salientar que preferimos enfatizar no instrumento a expectativa de que a resposta do participante fosse considerada uma ação diante da pressão recebida e não apenas uma reação. Assim, cada situação foi seguida pelas seguintes perguntas: Como você agiria? Como ele/a deveria ter agido?

A aplicação ocorreu, coletivamente, em horário escolar, combinada com as direções dos estabelecimentos de ensino e de acordo com consentimento dos estudantes, mediante exposição dos propósitos da pesquisa. 


\section{Análise de dados}

O material coletado foi organizado analiticamente, segundo diferentes retóricas de influência/ações antecipadas para agir/enfrentar as situações de pressão simuladas. Estas foram descritas primariamente em função de critérios semânticos, segundo algumas técnicas de análise de conteúdo (BARDIN, 1991). Porém, o sistema categorial criado por nós teve como propósito principal de fazer uma articulação com as teorias de influência social, conforme informadas na introdução do trabalho. As retóricas/ações se dividiram entre aceitações, recusas e não decisão. Em seguida, as frequências de respostas foram objeto de testes de qui-quadrado usando o software Biostat, comparando frequências de grupos a partir de teste geral (colunas por linhas) e partição (linha por linha).

\section{Resultados}

A seguir, estão listados os diferentes tipos de retóricas/ações antecipadas usados pelos participantes para enfrentar as situações de pressão. $\mathrm{O}$ instrumento foi elaborado para observar igualmente as antecipações de ações do personagem em cada interação simulada, conforme já mencionado. Contudo, em função da exiguidade de espaço não vamos apresentar os resultados relativos à análise deste último conjunto de dados. Ou seja: vamos apresentar apenas os resultados referentes à pergunta "Como você agiria?"; acompanhados de algumas ilustrações dos conteúdos identificados, acompanhadas de sexo ( $\mathrm{f}=$ feminino; $\mathrm{m}=$ masculino), idade e autodefinição étnica-racial (negro $=\mathrm{N}$; branco $=\mathrm{B}$; moreno $=\mathrm{M})$.

Aceita com cordialidade. Procura se submeter à pressão sem maiores aprofundamentos/justificativas, senão manifestar que aquele ato é para agradar ou corresponder a uma expectativa social majoritária: "eu carregaria por gentileza, sem dar na pinta que a conheço" (m, 16, M); "Carregaria, pois não custa nada ajudar os outros" (f, 17, B); "Pediria desculpa com educação, pois é superior a mim" (f, 17, N); "eu o ajudaria a levantar e oferecia a lavar a roupa dele" (f, 16, B); "falaria que foi sem querer que bati no carro dele" (m, 16, B); "Para não deixar o professor mal eu falaria que tinha lido" (m, 17, B); "iria sem preconceito" (m, 15, M); "dançaria porque sou quase do tamanho do anão" (f, 17, N); "Esqueço os meus amigos e faço este favor" (f, 16, N). Aceita sem justificativa. É a submissão que não quer ou não pode manifestar as razões do ato, sem que haja expressão de boas maneiras: "Eu a ajudaria" (f, 14, M). Aceita por interesse do outro. Aceita outro seja beneficiado, ainda que busque averiguar se a situação está associada à desigualdade social vivida pelo outro ou pelo próprio personagem: "Carregaria se ela não conseguisse carregar" (f, 14, N); "Perguntaria se ele é cego" (f, 17, M); "Como ela assumiu o comando, seguiria as ordens dela" (f, 16, M). Aceita por interesse próprio. Aceita com condição de atender a interesse da própria pessoa pressionada, seja para evitar algo pior/adiando ou suspendendo o que fazia para diminuir seu sacrifício ou perda, ou satisfazer desejo ou necessidade: "se fosse rolar um dinheiro, carregaria com o maior prazer" (f, 17, N); "super mal não vou mais viajar e ainda vou ter prejuizo" (f, 13, M); "diria que já e iria dizendo logo outra coisa e pediria aplausos ao professor só 
para sair da situação" (m, 16, M); "se eu tivesse certeza de que eu ia conseguir eu aceitaria" (f, 17, N); "ajudaria porque o mundo gira, o que aconteceu com ele pode acontecer comigo" ( $\mathrm{m}, 16, \mathrm{~N})$; "Levaria um radinho para eu escutar $e$ deixava ele escutar a música dele" (f, 16, M). Recusa sem justificativa. Sem explicitar as razões da decisão/ato: "Não levaria" (f, 16, M); "Falaria que ele nunca me viu antes" (f, 16, N); "Não faria a entrevista" (f, 16, B); "Eu não dançaria" (f, 17, N); "não ficaria lá" (f, 16, M). Recusa com hostilidade. Física ou moral: "Não aceitaria, não sou carregador" (m, 19, M); "Leva você, pois não sou seu empregado" (f, 19, N); "Olharia bem para a cara dela e diria que não" (m, 17, B); "Não me conhece porque vocês não dão bola para nós, humildes" (m, 17, M); "falaria um monte de palavrões" (f, 16, M); "ah! baixava o barraco" (f, 17, N); "Chamava a atenção do hóspede" (f, 16, N); "falaria para ele limpar porque não está na casa dele" (m, 17, B); "eu dava um cascudo no velho e no dono" (m, 16, M). Recusa por interesse próprio. Recusa com condição de um benefício para o próprio participante ou para evitar algo desagradável para si mesmo, diminuindo seu prejuízo, sem levar em conta explicitamente as normas sociais: "Não aceitaria, porque se não desse certo, eu estaria desempregada" (f, 16, B); "Falava que não dava, pois estava atrasada para um encontro" (f, 16, B); "Não dançaria porque não gosto de dançar" (f, 15, N). Recusa com cordialidade. Procurando justificar-se usando as normas e convenções sociais de boas maneiras, etc., deslocando responsabilidade para o outro ou, enfim, afastando-se da situação de pressão: "Desculpe, estou com pressa" (f, 15, N); "eu não levaria, mas diria com educação" (f, 16, N); "Diria que não lhe pedindo desculpa por ser um ser humano e não [...]" (f, 17, B); "Desculpe, sou um cidadão comum" (f, 18, N); "Não tive oportunidade" (f, 16, N); "Diria que não tive o prazer de ler, mas que seria uma honra" (f, 16, M); "Falaria que o hotel não tolera esse tipo de acontecimento, me desculpe" (f, 16, M); "chegaria gentilmente e falaria com o lutador" (f, 15, B); "Falaria que não poderia dançar, porque estava com o pé machucado" (m, 17, M). Não decisão/Perplexidade/emoção. Perplexidade ou emoção pouco elaborada e explicitada do participante: "Ficaria muito chateada" (f, 16, B); "eu ficaria certamente sem ação e principalmente envergonhada" (f, 16, B); "desesperada" (f, 16, B); "ficava todo sem graça" (m, 17, B); "Talvez até dançaria, mas ficaria com vergonha" (m, 16, M). Não decisão/evitação. Procurando evitar a tomada de decisão, sem expressar a razão de modo explícito: "sairia do carro e diria que o seguro pagaria tudo" (m, 17, B); "Caso eu o conhecesse falaria de onde" (f, 17, N); "Eu ignoraria, fingindo que não vi" (f, 16, B). Não decisão/busca de acordo. Procurando encontrar um acordo com aquele que pressiona: "Se eu fosse, dividiria o peso" (m, 17, B): "Via de quem é a culpa e o que faria para ninguém sair prejudicado" (f, 17, N); "tentaria entrar num acordo com ela para não me prejudicar" (f, 16, B). Não sabe/não respondeu. "Não sei” (m, 16, M).

Antes de apresentarmos os resultados das análises estatísticas das retóricas de influência adotadas segundo os grupos étnicos autodefinidos, agrupamos as proporções de aceitações, recusas e não decisões para saber as tendências gerais. Assim, os $\mathrm{N}$ recusaram algo mais a pressão dos personagens majoritários $(\mathrm{N}=43 \% ; \mathrm{B}=28,5 \% ; \mathrm{M}=35,4 \%)\left(\chi^{2}=4.7406 ; \mathrm{gl}=1 ; \mathrm{p}<0,0295\right)$, mas os grupos ten- 
deram a aceitar ( $\mathrm{N}=43 \%$; $\mathrm{B}=54,2 \% ; \mathrm{M}=45,5 \%)$ e não decidir $(\mathrm{N}=14, \% ; \mathrm{B}=17,3 \%$; $\mathrm{M}=19,1 \%)\left(\chi^{2}=8,9117 ; \mathrm{gl}=4 ; \mathrm{p}<0,0633\right)$. Já as comparações intergrupais em relação aos personagens majoritários/minoritários não apresentaram diferenças significativas (aceitações: $\mathrm{N}=32,4 \% ; \mathrm{B}=29,3 \%$; $\mathrm{M}=32,1 \%$; recusas: $\mathrm{N}=55,8 \%$; $\mathrm{B}=55,1 \% ; \mathrm{M}=57,5 \%$; não decisão: $\mathrm{N}=11,7 \% ; \mathrm{B}=15,5 \% ; \mathrm{M}=10,2 \%)\left(\chi^{2}=3.3669\right.$; $\mathrm{gl}=4 ; \mathrm{p}<0,4984)$. Enfim, as comparações em relação aos personagens minoritários apresentaram pouca diferenciação intergrupal, o que foi acompanhado por uma polarização maior em termos de aceitação, recusa e praticamente baixas percentagens de não decisão $\left(\chi^{2}=5.2732 ; \mathrm{gl}=4 ; \mathrm{p}>0,2604\right)$, ainda que os morenos tenham mostrado alguma diferenciação quanto a não decisão $\left(\chi^{2}=4.2981 ; \mathrm{gl}=1\right.$; $\mathrm{p}>0,0382$ ) (aceitações: $\mathrm{N}=56,7 \% ; \mathrm{B}=61,3 \% ; \mathrm{M}=60,2 \%$; recusas: $\mathrm{N}=35,0 \%$; $\mathrm{B}=34,0 \% ; \mathrm{M}=30,3 \%$; não decisão: $\mathrm{N}=8,2 \% ; \mathrm{B}=4,6 \% ; \mathrm{M}=9,4 \%$ ).

Tabela 1 - Retóricas à pressão de personagens majoritários, segundo grupos étnicos.

\begin{tabular}{lccccccc}
\hline Retóricas/grupos & \multicolumn{2}{c}{ Negro } & \multicolumn{2}{c}{ Branco } & \multicolumn{2}{c}{ Moreno } \\
& f. & $\%$ & f. & $\%$ & f. & $\%$ \\
\hline Aceita com cordialidade & 16 & 14,9 & 58 & 23,2 & 42 & 15,8 \\
Aceitação sem justificativa & 8 & 7,5 & 20 & 8 & 13 & 4,9 \\
Aceita por interesse do outro & 5 & 4,7 & 1 & 0,4 & 5 & 1,8 \\
\cline { 2 - 3 } Aceita por interesse próprio & 17 & 15,9 & 56 & 22,5 & 61 & 23 \\
Recusa sem justificativa & 6 & 5,6 & 18 & 7,2 & 36 & 13,5 \\
Recusa com hostilidade & 11 & 10,3 & 14 & 5,6 & 28 & 10,5 \\
Recusa por interesse próprio & 11 & 10,3 & 30 & 12 & 24 & 9,1 \\
Recusa com cordialidade & 18 & 16,8 & 9 & 3,6 & 6 & 2,3 \\
Não decisão/Perplexidade & 3 & 2,8 & 22 & 8,8 & 21 & 7,9 \\
Não decisão/evitação & 8 & 7,5 & 8 & 3,5 & 14 & 5,3 \\
Não sabe/não responde & 1 & 0,9 & 2 & 0,8 & 5 & 1,8 \\
Não decisão/busca acordo & 3 & 2,8 & 11 & 4,4 & 11 & 4,1 \\
Total & 107 & & 249 & & 266 & \\
& & & & & & \\
\hline
\end{tabular}

$\chi^{2}=70.696 ; \mathrm{gl}=22 ; \mathrm{p}<0,0001$.

Assim, os $\mathrm{N}$ se destacaram em aceitar as pressões de personagens majoritários por interesse do outro $\left(\chi^{2}=8.1546 ; \mathrm{gl}=1 ; \mathrm{p}<0,0043\right)$; por recusarem com

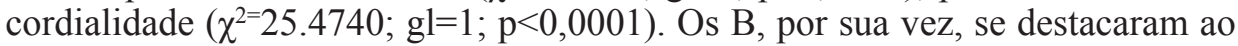
aceitarem com cordialidade $\left(\chi^{2}=5.9352 ; \mathrm{gl}=1 ; \mathrm{p}<0,0151\right)$. Os $\mathrm{M}$, enfim, recusaram sem justificativa $\left(\chi^{2}=8.1260 ; \mathrm{gl}=1 ; \mathrm{p}<0,0044\right)$. 
Tabela 2 - Retóricas à pressão de personagens majoritários-minoritários, segundo grupos étnicos.

\begin{tabular}{|c|c|c|c|c|c|c|}
\hline \multirow[t]{2}{*}{ Retóricas/grupos } & \multicolumn{2}{|c|}{ Negro } & \multicolumn{2}{|c|}{ Branco } & \multicolumn{2}{|c|}{ Moreno } \\
\hline & f. & $\%$ & f. & $\%$ & f. & $\%$ \\
\hline Aceita com cordialidade & 6 & 5,4 & 25 & 10,7 & 19 & 7,2 \\
\hline Aceitação sem justificativa & 12 & 10,8 & 15 & 6,4 & 24 & 9,1 \\
\hline Aceita por interesse do outro & 18 & 16,2 & 28 & 12 & 2 & 0,8 \\
\hline Aceita por interesse próprio & 0 & 0 & 0 & 0 & 40 & 15,2 \\
\hline Recusa sem justificativa & 22 & 19,8 & 44 & 18,9 & 56 & 21,2 \\
\hline Recusa com hostilidade & 8 & 7,2 & 11 & 4,7 & 18 & 6,8 \\
\hline Recusa por interesse próprio & 6 & 5,4 & 21 & 9 & 22 & 8,3 \\
\hline Recusa com cordialidade & 26 & 23,4 & 52 & 22,4 & 56 & 21,2 \\
\hline Não decisão/Perplexidade & 2 & 1,8 & 8 & 3,4 & 10 & 3,8 \\
\hline Não decisão/evitação & 2 & 1,8 & 14 & 6 & 10 & 3,8 \\
\hline Não responde/não sabe & 8 & 7,2 & 6 & 2,5 & 4 & 1,5 \\
\hline Não decisão/busca acordo & 1 & 0,9 & 8 & 3,4 & 3 & 1,1 \\
\hline Total & 111 & & 232 & & 264 & \\
\hline
\end{tabular}

$\chi^{2}=109.1588 ; \mathrm{gl}=22 ; \mathrm{p}<0,0001$.

Antes de apresentar as diferenciações, precisamos ressaltar que houve duas tendências gerais: de recusa sem justificativa e recusa com cordialidade. Ao lado disso, os $\mathrm{N}$ se diferenciaram ao aceitarem sem justificativa $\left(\chi^{2}=4.2686 ; \mathrm{gl}=1\right.$; $\mathrm{p}<0,0388)$ e por interesse do outro $\left(\chi^{2}=19.5294\right.$; gl=1; $\left.\mathrm{p}<0,0001\right)$ e por não responderem/não saberem $\left(\chi^{2}=5.3906 ; \mathrm{gl}=1 ; \mathrm{p}<0,0202\right)$. Os $\mathrm{M}$, enfim, se diferenciaram por aceitarem por interesse próprio $\left(\chi^{2}=62.5112 ; \mathrm{gl}=1 ; \mathrm{p}<0,0001\right)$.

Tabela 3 - Retóricas à pressão de personagens minoritários, segundo grupos étnicos.

\begin{tabular}{lcccccc}
\hline Grupos étnico-raciais/retóricas & \multicolumn{2}{c}{ Negro } & \multicolumn{2}{c}{ Branco } & \multicolumn{2}{c}{ Moreno } \\
& f. & $\%$ & f. & $\%$ & f. & $\%$ \\
\hline Aceita com cordialidade & 23 & 17,1 & 37 & 15,3 & 52 & 19,5 \\
Aceitação sem justificativa & 30 & 22,5 & 53 & 22 & 54 & 20,3 \\
Aceita por interesse do outro & 1 & 0,7 & 2 & 0,8 & 2 & 0,8 \\
Aceita por interesse próprio & 22 & 16,4 & 54 & 22,4 & 53 & 19,9 \\
Recusa sem justificativa & 10 & 7,5 & 16 & 6,7 & 13 & 4,9 \\
Recusa com hostilidade & 9 & 6,8 & 5 & 2 & 13 & 4,9 \\
Recusa por interesse próprio & 17 & 12,6 & 35 & 14,6 & 33 & 12,4 \\
Recusa com cordialidade & 11 & 8,2 & 25 & 10,4 & 21 & 7,9 \\
Não decisão/Perplexidade & 0 & 0 & 3 & 1,2 & 5 & 1,8
\end{tabular}




\begin{tabular}{lccccccc}
\hline Grupos étnico-raciais/retóricas & \multicolumn{2}{c}{ Negro } & \multicolumn{2}{c}{ Branco } & \multicolumn{2}{c}{ Moreno } \\
& f. & $\%$ & f. & $\%$ & f. & $\%$ \\
Não decisão/evitação & 2 & 1,5 & 2 & 0,8 & 7 & 2,7 \\
Não responde/não sabe & 7 & 5,2 & 2 & 0,8 & 4 & 1,6 \\
Não decisão/busca acordo & 2 & 1,5 & 7 & 3 & 9 & 3,3 \\
Total & 134 & & 232 & & 266 & \\
& & & & &
\end{tabular}

$\chi^{2}=25.5120 ; \mathrm{gl}=22 ; \mathrm{p}<0,2732$.

Os grupos se aproximaram em aceitações com cordialidade, aceitações sem justificativa e recusas por interesse próprio. Os $\mathrm{N}$ se diferenciaram, em menor medida, ao recusarem com hostilidade $\left(\chi^{2}=4.8235 ; \mathrm{gl}=1 ; \mathrm{p}<0,0281\right)$ e por não responderem/não saberem $\left(\chi^{2}=8.4513 ; \mathrm{gl}=1 ; \mathrm{p}<0,0036\right)$.

Enfim, os grupos étnicos/raciais comparados apresentaram certas variabilidades demográficas que podem ter favorecido algumas tendências de resposta, como as possivelmente advindas do item sexo/gênero. Assim, tivemos maior presença de participantes do sexo feminino tanto para negros quanto para morenos, o que não se deu com os brancos cujas amostras apresentaram equilíbrio para ambos os sexos/gêneros. Tendo em vista que essas análises de sexo/gênero - no presente trabalho - teriam de ser feitas com amostras muito reduzidas para os participantes do sexo masculino de negros e morenos, preferimos aprofundar esses resultados em outra oportunidade. Nesse sentido, acreditamos que outras variáveis biopsicossociais também alteram, intensificam ou determinam os resultados que obtivemos, cabendo mais pesquisas.

\section{DiscuSSÃo}

Durante a interação simulada para enfrentar a pressão provocada por personagens descritos como majoritários (poderosos), os participantes autodefinidos como negros, brancos e morenos apresentaram alguma diferenciação intergrupal, ao passo que em relação aos personagens majoritários/minoritários e minoritários houve certa diferenciação, mas não tão significativa.

Supomos que as autodefinições étnico-raciais sejam parte do processo histórico de relação intergrupal existente na sociedade, no sentido de regularidades sociais resultantes de experiência anterior, possibilidades (ou não) de acordo, partilha sociocultural e política, que alteram outros fatores mais situacionais. Assim, poderíamos mencionar que apesar de os negros terem também usado uma retórica de cordialidade - usada mais em decisões de recusa -, os brancos tenderam a aceitar as pressões provocadas por majoritários. A retórica de aceitação por interesse do outro teve destaque entre os negros, tanto com majoritários quanto majoritários-minoritários, indicando dúvida, sobre a necessidade e a propriedade da aceitação, assim como possibilidade de que as pressões provocadas por alguns grupos não estivessem encobrindo manipulações sociais. 
Apesar da relativa simplicidade das situações propostas - se comparadas às situações reais vividas pelos participantes na sociedade - , é possível avançar nosso conhecimento psicossocial a partir desses resultados.

Em primeiro lugar, é preciso dizer que autodefinir-se como negro na sociedade brasileira implica em ruptura com um processo histórico de paulatino branqueamento praticado por afro-brasileiros desde o fim do escravismo (MUNANGA, 1998). Ou seja, poderíamos considerar que os negros que se identificam com um grupo social minoritário étnico, e o tenham declarado numa pesquisa, estivessem agindo até certo ponto como minorias ativas. Ou seja, a autodenominação étnica é um passo preliminar importante, mas nem sempre livre de atuação, tornando-se um lugar (SANTOS, 1996) "corporal" de lutas sociais, em que os sujeitos sociais podem tanto se emancipar de regularidades simbólicas quanto se manter ligados a outras. Nesse sentido, as identidades sociais são construídas a partir de práticas sociais concretas em comunidades, escolas, entre outros ambientes sociais (GUARESCHI et al., 2002). Este estudo, embora não tivesse como meta o aprofundamento de identidades sociais, indicou a existência de padrões de representação e relacionamento que, em ultima instancia, derivam de identidades sociais, uma vez que as autodenominações étnicas parecem estar por detrás das ações em busca de sentido para as interações que propusemos com as situações simuladas. Nesse quadro, a dimensão étnica/racial passa a ter um papel formador importante, ainda que não tenha sido mencionada nem uma vez nas falas dos participantes para lidar com as situações propostas. Ou seja, tratar-se-ia de um orientador de condutas oculto, talvez consciente, algo que poderia ser investigado posteriormente.

Já os morenos, nas suas várias origens, indicam uma diferenciação que se problematiza na medida em que seu projeto de integração sociocultural não se completa. Embora os resultados tenham apontado certa tendência de ruptura entre os morenos (inclusive expressando mais recusa sem justificativa), acreditamos que sua maior frequência de respostas aceita por interesse próprio indique certo sentimento de legitimidade de expressão dos seus interesses, o que os colocaria próximos aos brancos em termos de status social. Ademais, os morenos estariam também buscando certa autonomia diante da situação social proposta. Até certo ponto, podemos atribuir este fato ao ambiente sociopolítico atual em que há certo clima de oposição e rebeldia entre jovens, gerando as respostas que obtivemos.

Já os brancos destacaram-se, como já dissemos, pela aceitação da pressão dos personagens majoritários para enfrentar as situações propostas. Para tanto, os brancos expressaram seu próprio interesse, ainda que tenham usado a retórica de cordialidade com os considerados mais poderosos, em que se destacaram isoladamente. Supomos que a situação de reconhecimento maior deste grupo étnico-racial ofereça-lhe legitimidade suficiente para explicitar seus próprios interesses sem inibição, conduta que foi mais explicitada por morenos no caso dos personagens majoritários-minoritários, conforme dissemos. Contudo, podemos dizer que existe certo controle social que inibiria a expressão geral de interesses por parte dos grupos observados. 
Apesar da crescente importância da racionalização na vida cotidiana para muitos (no sentido de maximizar benefícios e minimizar perdas), as retóricas explicitadas indicaram a importância de aspectos psicossociais como as expectativas de interações cordiais. De modo que os negros, ao não aceitarem a pressão majoritária ,explicitando ao mesmo tempo a cordialidade, possivelmente procuravam atenuar um efeito negativo da recusa, indicando uma retórica menos segura sobre as reações dos outros personagens sociais. Assim, é necessário um patamar mínimo de reconhecimento social, sobretudo dos grupos que não o desfrutam na sociedade, mesmo para aceitar as pressões de grupos majoritários. Boa parte da linguagem política adotada na atualidade considera como mais legítimos aspectos ligados aos interesses econômicos ou que impliquem em confirmação da hierarquia de poder/ascendência social existente. Ou seja, as formas de influência social adotadas por indivíduos identificados a grupos étnicos indicaram diferenciação, sobretudo quanto às relações com os grupos superiores, uns mostrando expectativa de integração e outros de rejeição, sendo que a integração mencionada não traria nenhum confronto entre valores ou normas. Assim, a competição social que observamos se daria também no plano horizontal da sociedade, sendo um dos eixos principais o étnico, manifestado ao reagir diante da pressão de minorias mais apelativas de valores humanos e religiosos do que propriamente propositivas ou em conflito com normas hierarquicamente hegemônicas.

O motivo da submissão em relação aos grupos superiores poderia residir, por exemplo, em representações a respeito dos personagens em interação. Parte da dificuldade para levar adiante um projeto político supragrupal derivaria da insistência em não levar em conta esses confrontos sociais que ocorrem na sociedade. Por exemplo, a crença provável entre os brancos de que os poderosos possam ser ainda mais poderosos do que eles o são na realidade, levando-os à submissão mais pronunciada e, mesmo, à aceitação da pressão, conforme observamos. Igualmente, sustentaria a existência de uma hierarquia social a crença de que a superioridade dos brancos é legítima e não deve ser alterada, uma vez que os negros colocaram isso em xeque com dúvidas sobre as intenções verdadeiras das pressões exercidas sobre eles; e, mesmo, a partir de não explicitação de resposta (não sabe/não responde). Nesse sentido, os discursos sobre os grupos que circulam na sociedade podem afetar a decisão a respeito da forma de agir intergrupal, o que derivaria de identificações e sintonias discursivas inter e intragrupais (MORITZ-SCHWARCZ, 1987; PEREIRA, TORRES; ALMEIDA, 2003), independente de uma realidade psicofísica qualquer.

Enfim, constatamos que as situações de pressão por parte de personagens majoritários/minoritários geraram diferenças significativas, sobretudo para os morenos, que apresentaram alta frequência de aceitações por interesse próprio. Até certo ponto se pode perguntar se não haveria aqui um argumento para justificar a aceitação de pressão de uma minoria, como se tivesse ocorrido algo similar à dissonância cognitiva (FESTINGER, 1975[1957]), gerando a busca de razões ao nível individual. Ao lado disso, poderíamos interpretar tal resultado como uma tentativa, por parte desses que aceitaram a pressão de uma minoria com poder, 
de desfazer a influência exercida em termos psicossociais. Assim, a possibilidade de existir uma minoria social com algum poder parece gerar um conflito interno maior, o que pode vir a ser mais estudado.

Já no caso da interação simulada com minorias, observamos inversão da retórica de ação, a qual tendeu para a aceitação, inclusive com menores índices de não decisão de resposta, confirmando parcialmente alguns achados de Moscovici e Pérez (2007); no sentido de as minorias como vítimas obterem efeito de aceitação imediato, ainda que sem alterar as normas/ideologias que mantêm as desigualdades. Na realidade, poderíamos dizer que existe antes de tudo uma ambivalência representacional, conforme já foi observado em outros estudos. Assim, Guillaumin (1972) encontrou na imprensa francesa a tendência de as minorias sociais serem representadas ressaltando algo idealizado dos seus passados; em contraste com um presente degradado ou explicitamente negativo, como envolvimento com crime, etc., ou ainda, como foi encontrado em outro estudo no Brasil, como ausentes e invisíveis (LIMA; ALMEIDA, 2010). Tais fenômenos podem se manifestar historicamente como estando associado à indiferença em relação à cultura da qual se pretende afastar ou mesmo eliminar. Igualmente, acreditamos se tratar de manifestação de paternalismo ou tutela do grupo majoritário ou identificado com o mesmo em relação ao grupo minoritário, cumprindo funções de controle social de alguém que pode parecer ameaçador, imediata ou futuramente.

Ou seja, estaríamos diante de duas éticas/normas de ação que tenderiam, de um lado, a formas altruísticas com grupos minoritários impossibilitados ou demandando reconhecimento e, de outro, a menor tolerância em relação aos grupos majoritários-minoritários, que não explicitam dependência social. Apesar de grande aproximação entre os grupos, a situação se apresentaria de modo diferente, sobretudo para os negros em relação aos personagens majoritários. Primeiro, a sua relativa tendência de não manifestar interesse próprio diante das possibilidades de troca. Em seguida, haveria um retraimento e, mesmo, intenção de hostilidade manifestada diante dos grupos com menor ou nenhum poder, talvez indicando menor uso de formas altruísticas em espaços fora de suas comunidades (SOUZA FILHO, 2011), cabendo mais estudos.

Apesar da variedade de personagens minoritários propostos, pode-se afirmar que, em alguns contextos da sociedade, as possibilidades de solidariedade interminoritária precisam ser mais incentivadas. Esse recuo intragrupal poderia implicar perda de oportunidade de explicitar interesses e negociar outras formas de troca social. Enfim, os resultados aqui discutidos merecem mais estudos até mesmo em função das limitações amostrais. 


\section{REFERÊNCIAS}

APFELBAUM, E. La psychologie sociale à l'épreuve des femmes: l'impensé des rapports de domination. Revue Internationale de Psychologie Sociale, [S.1.], v. 10, n. 2, p. 153-169, 1997.

BARDIN, L. L'analyse de contenu. Paris: P.U.F, 1991.

BASTIDE, R. As religiões africanas no Brasil. São Paulo: EDUSP, 1971. v. I e II.

BERKOWITZ, L. (Ed.) The Frustration aggression hypothesis revisited. In: . Roots of aggression. New York: Atherton, 1969. p. 1-28.

DOISE, W. (Ed.). Expériences entre groupes. Paris: Mouton, 1979.

DOLLARD, J. et al. Frustration and aggression. New Haven: Yale University Freer, 1939.

FAUSTO, B. História do Brasil. São Paulo: Edusp, 1994.

FESTINGER, L. Teoria da dissonância cognitiva (1957). Tradução de Eduardo Almeida. Rio de Janeiro: J. Zahar, 1975.

FRENCH, J. R. P.; RAVEN, B. The bases of social power. In CARTWRIGHT, D. (Ed.) Studies in Social Power. Ann Arbor: University of Michigan, 1959. p. 118-149.

GUARESCHI, N. M. F. et al. As relações raciais na construção das identidades. Psicol. Estud., Maringá, v. 7, n. 2, p. 55-64, jul./dec. 2002.

GUILLAUMIN, C. L'idéologie raciste. Paris: Mouton, 1972.

INSTITUTO BRASILEIRO DE GEOGRAFIA E ESTATÍSTICA. Pesquisa Nacional por Amostra de Domicílio. Rio de Janeiro: IBGE, 1976.

INSTITUTO BRASILEIRO DE GEOGRAFIA E ESTATÍSTICA. Censo Demográfico de 2000. Rio de Janeiro: IBGE, 2000. Disponível em: <http://www. ibge.gov.br/home/presidencia/noticias/20122002censo.shtm>. Acesso em: 16 nov. 2011.

LÉVI-STRAUSS, C. Raça e história. In: LÉVY-STRAUSS, C. (Org.). Raça e Ciência. São Paulo: Perspectiva, 1970. v. 1, p. 231-270.

LEWIN, K. Resolving social conflicts. New York: Harper \& Row, 1948. 
LIMA, M. E.; ALMEIDA, A. M. M. de Representações sociais construídas sobre os índios em Sergipe: ausência e invisibilização. Paidéia, [S.1.], v. 20, n. 45, p. 17-27, 2010.

MAGGI, Y. Aqueles a quem foi negada a cor do dia: as categorias cor e raça na cultura brasileira. In: MAIO; M. C.; SANTOS, R. V. (Org.). Raça, ciência e sociedade. Rio de Janeiro: Fiocruz/CCBB, 1996. p. 225-234.

MORITZ-SCHWARCZ, L. Retrato em branco e negro. São Paulo: Companhia das Letras, 1987.

MOSCOVICI, S. Psychologie des minorités actives. Paris: PUF, 1979. [Psicologia das minorias ativas. Tradução de Pedrinho Guareschi. Petrópolis, RJ: Vozes, 2011.]

MOSCOVICI, S. (Org.). Les formes élémentaires de l'altruisme. In: Psychologie sociale des relations à autrui. Paris: PUF, 1994. p. 71-86.

MOSCOVICI, S.; PAICHELER, G. Social comparison and social recognition: two complementary processes of identification. In: TAJFEL, H. (Ed.). Differention between social groups. Londres: Academic, 1978. p. 251-266.

MOSCOVICI, S.; PÉREZ, J. A. A study of minorities as victims. Eur. J. Soc. Psychol, [S.1.], v. 37, n. 4, p. 725-746, 2007.

MUGNY, G.; PAPASTAMOU, S. The power of minorities. Londres: Academic, 1982.

MUNANGA, K. Rediscutindo a mestiçagem no Brasil. Petrópolis, RJ: Vozes, 1998.

OLIVEIRA, I. Desigualdades raciais: construções da infầncia e da juventude. Niterói: Intertexto, 1999.

PEREIRA, C.; TORRES, A. R. T.; ALMEIDA, S. T. Um estudo do preconceito na perspectiva das representações sociais: uma análise da influência de um discurso justificador de discriminação no preconceito racial. Psicologia: Reflexão e Crítica, [S.1.], v. 16, n. 1, p. 95-107, 2003.

PHILOGÈNE, G. From Black to African American: a new social representation. Westport: Praeger, 1997.

SANTOS, J. R. dos O negro como lugar. In: MAIO, M. C.; SANTOS, R.V. (Org.). Raça, ciência e sociedade. Rio de Janeiro: Fiocruz/CCBB, 1996. p. 219-223. 
SEYFERTH, G. Construindo a nação: hierarquias raciais e o papel do racismo na política de imigração e colonização. In: MAIO, M. C.; SANTOS, R. V. (Org.). Raça, ciência e sociedade. Rio de Janeiro: Fiocruz/CCBB, 1996. p. 41-58.

SCHWARTZMAN, S. Raça e etnia. In: . As causas da pobreza. Rio de Janeiro: F.G.V, 2004. p. 101-117.

SOUZA FILHO, E. A. de. Representações antecipatórias em situações de pressão social, segundo grupo étnico-racial autodefinido, Temas em Psicologia, [S.1.], v. 19, n. 1, p. 163-177, 2011.

TAJFEL, H. Intergroup behaviour. In: TAJFEL, H.; FRASER, C. (Ed.) Introducing social psychology. Harmondsworth: Penguin, 1978. p. 401-422.

TAJFEL, H. Human groups and social categories: studies in social psychology. Cambridge: Cambridge University, 1981.

Recebido em: 02 de março de 2012 Aceito em: 13 de novembro de 2013 


\section{Anexo I}

Abaixo as situações simuladas apresentadas aos participantes, que foram seguidas por solicitação de respostas às seguintes questões: Diante da situação apresentada como você agiria? Como ele/a (personagem da situação) deveria ter agido?

- Você está no elevador e descobre que uma famosa apresentadora de TV também está lá, ela pede para você carregar uma bolsa pesada até o lugar onde ela está indo, que é bem longe. [majoritário]

-O prefeito da cidade estava passando um dia pela rua e você esbarra nele, de modo que ele cai no chão e suja toda a roupa dele. Ele fica parado e pergunta se conhece você de algum lugar. [majoritário]

-Um professor é homenageado por uma escola e convidam você para representar os estudantes durante uma cerimônia. Na hora ele pergunta, na frente de todos, se você já leu um livro que ele escreveu e que você não leu. [majoritário-minoritário]

-Você está numa festa e um dos convidados/as é um(a) anão/ã. Ele(a) pede para dançar com você, na frente de todos, inclusive seus amigos e parentes. [minoritário]

-Você ia dirigindo o seu carro novo na avenida, quando seu carro bate noutro e fica todo amassado. Ao volante estava um grande empresário. Acontece que você já tinha programado uma viagem de férias com o carro. [majoritário]

-Uma mulher assume o comando de uma empresa multinacional onde você trabalha e que reformulou os métodos de trabalho, incluindo a dispensa de funcionários, remuneração segundo produtividade, etc. Você foi convocado/a para uma entrevista com a executiva quando ela lhe propõe uma melhora salarial mediante participação em um projeto de risco que, se não der certo, implicará em perda do emprego. [majoritário-minoritário]

- Um senhor indiano que mora perto de sua casa e fala português com dificuldade, pede para você preencher um formulário para ele pleitear um emprego numa empresa no Brasil. Mas, o formulário deve ser enviado pelos correios imediatamente, pois é o último dia do prazo de inscrição e você está apressado/a para ir se encontrar com os amigos em pleno sábado à tarde. [minoritário]

-Você está passando férias numa pequena cidade à beira da praia, onde só há um quiosque para ouvir música e se distrair. O lugar é frequentado por um velhinho aposentado que, aparentemente, passa o dia inteiro lá e insiste em ouvir músicas que você não gosta. Acontece que o dono do quiosque apoia o velhinho, pois ele é um bom freguês. [minoritário]

-Você estava trabalhando na portaria de um hotel quando você viu um atleta, lutador de box, pôr os pés totalmente sujos de lama sobre uma mesinha de mármore, sabendo que o gerente não tolera qualquer sinal de pó no mobiliário. Você corria o risco de se indispor com o hóspede e/ou com o gerente. [majoritário-minoritário] 
